University of Nebraska - Lincoln

DigitalCommons@University of Nebraska - Lincoln

6-2007

\title{
Ferromagnetic Multipods Fabricated by Solution Phase Synthesis and Hydrogen Reduction
}

\author{
Y. C. Sui \\ University of Nebraska - Lincoln \\ Y. Zhao \\ University of Nebraska - Lincoln \\ Sitaram S. Jaswal \\ University of Nebraska-Lincoln, sjaswal1@unl.edu \\ Xingzhong Li \\ University of Nebraska-Lincoln, xli2@unl.edu \\ David J. Sellmyer \\ University of Nebraska-Lincoln, dsellmyer@unl.edu
}

Follow this and additional works at: https://digitalcommons.unl.edu/mrsecfacpubs

Part of the Materials Science and Engineering Commons

Sui, Y. C.; Zhao, Y.; Jaswal, Sitaram S.; Li, Xingzhong; and Sellmyer, David J., "Ferromagnetic Multipods Fabricated by Solution Phase Synthesis and Hydrogen Reduction" (2007). Faculty Publications: Materials Research Science and Engineering Center. 69.

https://digitalcommons.unl.edu/mrsecfacpubs/69

This Article is brought to you for free and open access by the Materials Research Science and Engineering Center at DigitalCommons@University of Nebraska - Lincoln. It has been accepted for inclusion in Faculty Publications: Materials Research Science and Engineering Center by an authorized administrator of DigitalCommons@University of Nebraska - Lincoln. 


\title{
Ferromagnetic Multipods Fabricated by Solution Phase Synthesis and Hydrogen Reduction
}

\author{
Y. C. Sui, Y. Zhao, J. Zhang, S. Jaswal, X. Z. Li, and D. J. Sellmyer \\ Department of Physics and Astronomy and Nebraska Center for Materials and Nanoscience, University of Nebraska, \\ Lincoln, NE 68588-0111 USA
}

\begin{abstract}
A simple approach combining pyrolysis and hydrogen reduction is formulated for making ferromagnetic-branched nanostructures called Co multipods. The $\mathrm{CoO}$ multipods (branched nanostructures) were produced through the pyrolysis of cobalt-oleate in octadecane at $280{ }^{\circ} \mathrm{C}$ with the presence of oleic acid under the protection of pure nitrogen. The angles between the nearest arms are $90^{\circ}$. After the reduction of the branched $\mathrm{CoO}$ nanostructures in flowing hydrogen gas in a tubular oven at $290{ }^{\circ} \mathrm{C}$, the $\mathrm{CoO}$ is reduced to pure cobalt with hexagonal crystal structure and the branched shapes are retained. Anisotropic magnetic properties were found for cobalt multipods on silicon substrates.
\end{abstract}

Index Terms-Co multipods, chemical synthesis, hydrogen reduction, magnetically anisotropic.

\section{INTRODUCTION}

A VARIETY of nanofabrication techniques have been developed for the purpose of shape-controlled synthesis, especially the fabrication of 1-D nanostructures, including VLS (vapor-liquid-solid) and biologically assisted growth, template-mediated growth, etc. [1]-[6]. Guided growth by anodized alumina templates is an example demonstrating that multibranched carbon nanotubes, magnetic nanowires, and nanotubes can be developed easily through chemical or electrochemical deposition within pores [3]-[5]. Beyond that, solution phase reaction has been demonstrated to be a powerful way for making nanocrystals with a tight size distribution and various shapes, such as spheres, disks, rods, multipods, etc. New functional materials might emerge if nanocrystals of higher complexity than those with simple geometries (spheres, rods, disks) could be produced. Recently, multipods have attracted much attention owing to their potential use as building blocks in the fabrication of complex, multiterminal devices through self assembly [7]-[9]. The synthesis of nanostructures with complex geometries has been a challenging but exciting research area.

Multipods or multibranched inorganic nanostructures are often made of type II-VI semiconductors, such as CdSe, CdS, etc. [10], [11]. Recently, rhodium multipods were made by a polyol process using rhodium chloride as the precursor of $\mathrm{Rh}$ [12]. Until now, no ferromagnetic magnetic multibranched nanostructure have been fabricated by the colloidal method. Here, we demonstrate that Co multibranched magnetic nanostructures, named multipods, can be produced through the combination of pyrolysis with hydrogen reduction.

\section{EXPERIMENTAL METHODS}

n-octadecane (technical grade), $\mathrm{CoCl}_{2} \cdot 6 \mathrm{H}_{2} \mathrm{O}$, oleic acid (technical grade) were obtained from Aldrich and sodium oleate from TCI, respectively. No purification was applied before synthesis reactions. Co-oleate was used as precursor

Digital Object Identifier 10.1109/TMAG.2007.894204 for the fabrication of $\mathrm{CoO}$ nanostructures. It was prepared in the laboratory at room temperature. Briefly, $10 \mathrm{mmol}$ sodium oleate and $5 \mathrm{mmol} \mathrm{CoCl} 2 \cdot 6 \mathrm{H}_{2} \mathrm{O}$ were dissolved in a $30 \mathrm{ml}$ solvent mixture of hexane, water, and alcohol $(10 \mathrm{ml}$ for each solvent). After vigorous magnetic stirring for $5 \mathrm{~min}$, they were transferred to a separation funnel to remove water. Distilled water was added to wash the Co-oleate five more times. Finally, the cobalt-oleate was dried in a vacuum to remove residual solvents. Because Co-oleate is not stable in air, it is highly desirable to use the freshly prepared Co-oleate. For the preparation of $\mathrm{CoO}$ multipods, $1 \mathrm{mmol}$ Co-oleate and $0.05 \mathrm{mmol}$ oleic acid were dissolved in $10 \mathrm{~g}$ octadecane, heated to $280^{\circ} \mathrm{C}$ for $1 \mathrm{~h}$ under the protection of nitrogen gas. The $\mathrm{CoO}$ multipods were precipitated out by adding alcohol and centrifugation. They were dissolved in hexane and drop-casted onto silicon substrates or carbon-coated copper grids for hydrogen reduction and other characterizations. X-ray diffraction (XRD) analysis was carried out with $\mathrm{Cu} \mathrm{K}_{\alpha}$ radiation. Hydrogen reduction was carried out in a home-made tubular oven with flowing hot hydrogen gas. Magnetic properties were measured by a quantum design superconducting quantum interference device (SQUID) magnetometer.

\section{RESUlTS AND DISCUSSION}

\section{A. Preparation of Branched CoO Nanoelements}

Fig. 1(a) is a TEM image of $\mathrm{CoO}$ multipods created by pyrolysis of Co-oleate in octadecane with the presence of a proper amount of oleic acid under an atmosphere of nitrogen gas. Both cross and T-shape Co oxide nanostructures were formed. It is interesting to note that nearly all of the nanostructures are $\mathrm{CoO}$ multipods, which means a very high yield for a synthetic chemical process. Arm lengths and diameters of the multipods are about 30 and $10 \mathrm{~nm}$, respectively. It is obvious to see that each multipod has a cube-like center, which may serve as nuclei for the subsequent formation of branched $\mathrm{CoO}$ nanostructures. Fig. 2(a) and (b)shows the XRD patterns of the branched $\mathrm{CoO}$ nanostructures prepared at the same temperature but for a different time. The branched nanostructures consist of two different phases. Phase 1 is a zinc-blende cubic oxide with lattice parameter a $=4.55 \AA$; phase 2 is also a cubic structure 


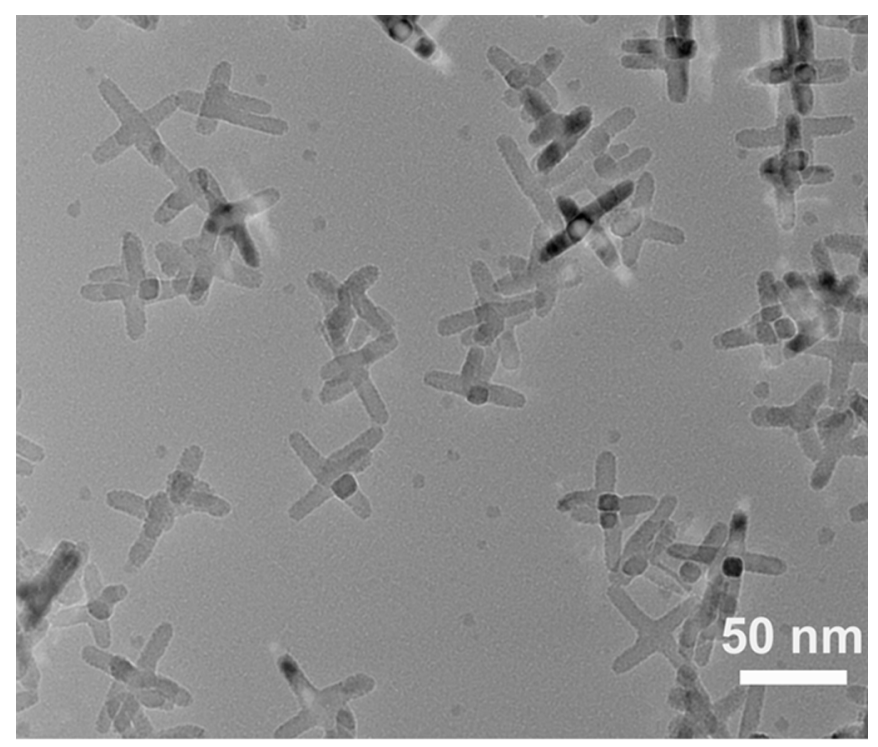

(a)

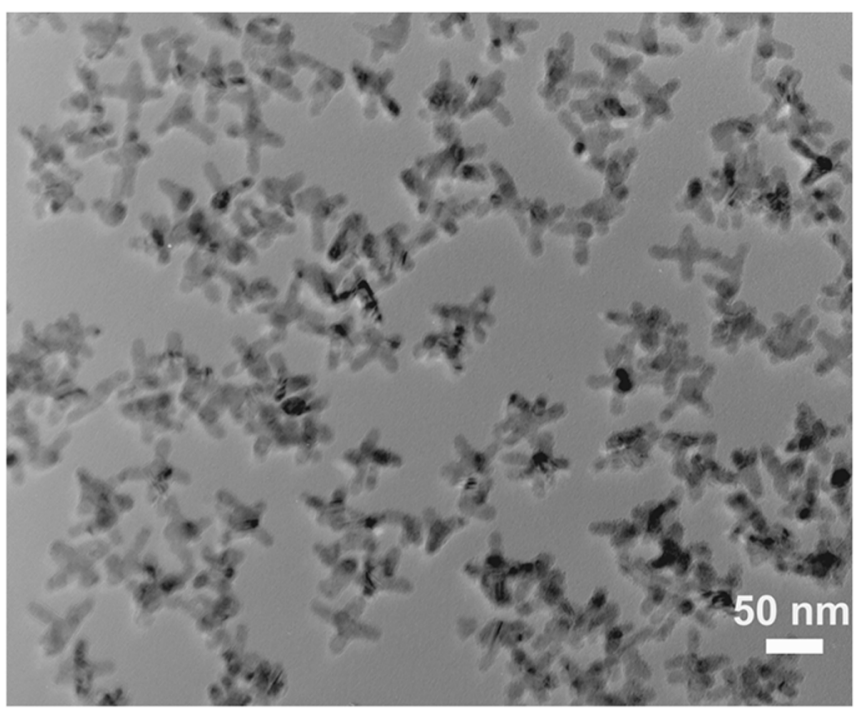

(b)

Fig. 1. (a) $\mathrm{CoO}$ multipods and (b) Co multipods on carbon-coated copper grid produced by hydrogen reduction at $290^{\circ} \mathrm{C}$ for $1.5 \mathrm{~h}$.

with lattice parameter $\mathrm{a}=4.263 \AA$. When the pyrolysis is carried out for a longer time, the ratio of phase 2 to phase 1 increases. Considering Fig. 1(a) with Fig. 2(a) and (b), it is reasonable to speculate that the cube-like centers appearing in Fig. 1 may correspond to phase 1, and the arms may correspond to phase 2. During the pyrolysis of Co-oleate in octadecane with the addition of oleic acid, $\mathrm{CoO}$ with zinc-blende structure prefers to nucleate due to the low surface energy [13]. As soon as the nucleation is accomplished, the growth of branched structure prefers the phase 2 structure. The combination of nucleation and subsequent growth results in the formation of branched $\mathrm{CoO}$ nanostructures with two different phases. Phase 1 remains almost the same when nucleation is finished. Continuous growth with extended heating time means more phase 2 , so the amount ratio of phase 2 to phase 1 increases with extended pyrolysis time, as shown by Fig. 2(a) and (b).

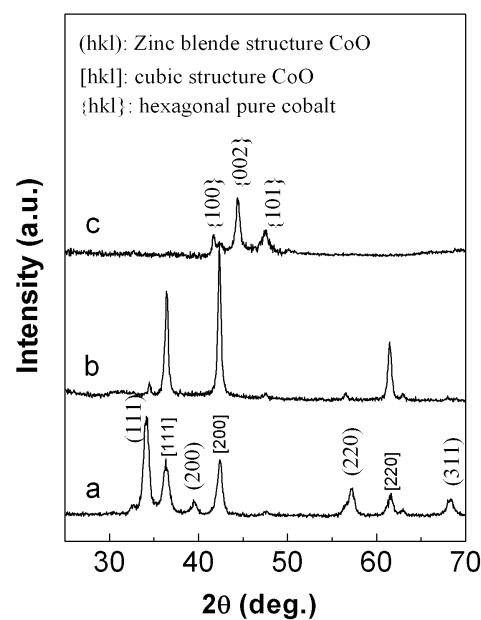

Fig. 2. XRD patterns of $\mathrm{CoO}$ multipods $\left(\mathrm{a}: 280^{\circ} \mathrm{C}-1 \mathrm{~h}\right.$; b $\left.-280^{\circ} \mathrm{C}-2.5 \mathrm{~h}\right)$ and Co multipods (c) made by hydrogen reduced at $290^{\circ} \mathrm{C}$.

Additional evidence by high-resolution TEM is under way to verify this growth model.

We observed that $\mathrm{CoO}$ multipods can be obtained only when the pyrolysis is carried out under the protection of nitrogen gas. When the pyrolysis is carried out in open air with or without oleic acid, the branched morphology cannot be obtained. Zettsu et al. observed that continuous bubbling of Ar during the synthesis greatly improved the stability of branched Rh nanocrystals, and $\mathrm{Rh}$ multipods can be synthesized in high yield when anhydrous $\mathrm{Na}_{3} \mathrm{RhCl} 6$ (rather than $\mathrm{RhCl} 3 \cdot \mathrm{nH} 2 \mathrm{O}$ ) is used as a precursor of $\mathrm{Rh}$; the authors believe that oxidative etching and Ostwald ripening would transform the branched Rh nanocrystals into spheres. Although the mechanisms for the formation of $\mathrm{CoO}$ cross or branched $\mathrm{Rh}$ nanostructures may be different, they have surprisingly similar features during the formation process of the branched nanostructures. That is, the presence of oxygen is detrimental to the formation of multipods of either Rh metal or $\mathrm{CoO}$, which deserves further investigation, especially for the $\mathrm{CoO}$ multipods produced in this work.

\section{B. Crystal Structural Change and Magnetic Properties}

When the $\mathrm{CoO}$ multipods were exposed to hot flowing hydrogen gas, the oxygen is taken away, and branched pure cobalt nanostructures are left. Fig. 2(c) is the XRD pattern of branched cobalt nanostructures on the $\mathrm{Si}$ substrate indicating the hexagonal crystal structure. The reduction temperature is critical for obtaining cobalt multipods. If the hydrogen reduction is carried out at $340{ }^{\circ} \mathrm{C}$, the branched nanostructures are destroyed, and only large cobalt particles are formed on the substrate. Fig. 1(b) shows branched Co nanostructures produced by hydrogen reduction of their cobalt oxide precursors on a carbon-coated copper grid at $290^{\circ} \mathrm{C}$. In cubic cobalt oxide, the ion diameters of Co and $\mathrm{O}$ are $1.09 \AA$ and $1.26 \AA$, respectively, which means that oxygen comprises more than half the volume of cobalt oxides. As soon as the oxygen was removed during hydrogen reduction, branched Co nanoelements were formed with a size smaller than their $\mathrm{CoO}$ precursors; meanwhile, the crystal structure transformed from cubic $\mathrm{CoO}$ to the hexagonal structure of pure cobalt, as shown in Fig. 1(a) and (c). 


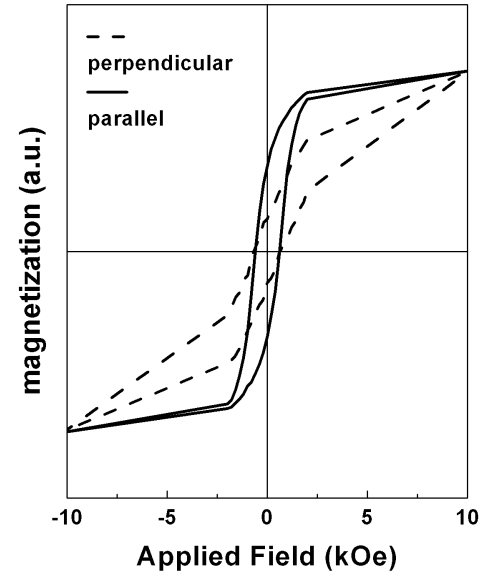

Fig. 3. Hysteresis loops for Co multipods on silicon substrate measured in-plane and out-of-plane.

Cobalt multipods extend their arms within the plane of the substrate [Fig. (1b)]. When the magnetic loops are measured in-plane, they exhibit higher remanance than those measured out-of-plane but have the same intrinsic coercivity. Both loops are shown in Fig. 3. The difference in remanance is caused mainly by shape anisotropy.

\section{CONCLUSION}

Pyrolysis of organometallic compounds in organic solvents was demonstrated to be a powerful way of making nanostructures with geometries of being both simple (spherical, nanorods) and highly complex (multipods). $\mathrm{CoO}$ multipods can be produced in very high yield by the thermal pyrolysis of cobalt oleate in octadecane under the protection of nitrogen gas. It is noteworthy to mention that the presence of oxygen definitely inhibits the formation of $\mathrm{CoO}$ multipods. When the branched $\mathrm{CoO}$ nanostructures are reduced by hot hydrogen gas at proper temperature, pure cobalt multipods were produced. Anisotropic magnetic properties were observed for Co multipods on silicon substrates.

\section{ACKNOWLEDGMENT}

This work is supported by the DOE, NSF-MRSEC, INSIC, NRI, and NCMN. The authors would like to thank B. Jones for his technical support.

\section{REFERENCES}

[1] J. T. Hu, T. W. Odom, and C. M. Lieber, "Chemistry and physics in one dimension: Synthesis and properties of nanowires and nanotubes," Acc. Chem. Res., vol. 32, no. 5, pp. 435-445, 1999.

[2] E. Braun, Y. Eichen, U. Sivan, and G. Ben-Yoseph, "DNA-Templated assembly and electrode attachment of a conducting silver wire," $\mathrm{Na}$ ture, vol. 391, no. 6669, pp. 775-778, 1998.

[3] Y. C. Sui, D. R. Acosta, J. A. Gonźlez-León, A. Bermúdez, J. Feuchtwanger, B. Z. Cui, J. O. Flores, and J. M. Saniger, "Structure, thermal stability, and deformation of multibranched carbon nanotubes synthesized by CVD in the AAO template," J. Phys. Chem. B., vol. 105, no. 8, pp. 1523-1527, 2001.

[4] Y. C. Sui, R. Skomski, K. D. Sorge, and D. J. Sellmyer, "Nanotube magnetism," Appl. Phys. Lett., vol. 84, no. 9, pp. 1525-1527, 2004.

[5] D. J. Sellmyer, M. Zhen, and R. Skomski, "Magnetism of Fe, Co and Ni nanowires in self-assembled arrays," J. Phys.: Condens. Matter., vol. 13, no. 25, pp. R433-R460, 2001.

[6] K. An, N. Lee, J. Park, S. C. Kim, Y. Hwang, J. G. Park, J. Y. Kim, J. H. Park, M. J. Han, J. Yu, and T. Hyeon, "Synthesis, characterization, and self-assembly of pencil-shaped $\mathrm{CoO}$ nanorods," J. Amer. Chem. Soc., vol. 128, no. 30, pp. 9753-9760, 2006.

[7] D. L. Wang and C. M. Lieber, "Nanocrystals branch out," Nat. Mater., vol. 2, no. 6, pp. 355-356, 2003.

[8] L. Manna, D. J. Milliron, A. Meisel, E. C. Scher, and A. P. Alivisatos, "Controlled growth of tetrapod-branched inorganic nanocrystals," Nat. Mater., vol. 2, no. 6, pp. 382-385, 2003.

[9] Y. C. Sui, Y. Zhao, M. Daniil, X. Z. Li, and D. J. Sellmyer, "FePt clusters synthesized by thermal pyrolysis of $\mathrm{Fe}$ and $\mathrm{Pt}$ compounds in organic solvent," J. Appl. Phys., vol. 99, no. 8, 2006, art. No. No. 08G704,

[10] X. G. Peng, "Mechanisms for the shape-control and shape-evolution of colloidal semiconductor nanocrystals," Adv. Mater., vol. 15, pp. 459-463, 2003.

[11] Y. W. Jun, S. M. Lee, N. J. Kang, and J. Cheon, "Controlled synthesis of multi-armed cds nanorod architectures using monosurfactant system," J. Amer. Chem. Soc., vol. 123, no. 21, pp. 5150-5151, 2001.

[12] N. Zettsu, J. M. McLellan, B. Wiley, Y. Yin, Z. Y. Li, and Y. Xia, "Synthesis, stability, and surface plasmonic properties of rhodium multipods, and their use as substrates for surface-enhanced raman scattering," Angew. Chem. Int. Ed., vol. 45, pp. 1288-1292, 2006.

[13] C. Y. Yeh, Z. W. Lu, S. Froyen, and A. Zunger, "Zinc-Blende-Wurtzite polytypism in semiconductors," Phys. Rev. B, vol. 46, no. 16, pp. 10086-10097, 1992.

Manuscript received October 31, 2006 (e-mail: yunchengsui @gmail.com). 